\title{
STRAIN RATE BEHAVIOR OF PURE ALUMINUM IN CONICAL INDENTATION WITH DIFFERENT INDENTER CONTROL METHODS
}

\author{
TSUYOSHI KAMI ${ }^{1}$, HIROYUKI YAMADA $^{2}$, NAGAHISA OGASAWARA $^{2} \&$ XI CHEN $^{3}$ \\ ${ }^{1}$ Graduate School of Science and Engineering, National Defense Academy, Japan. \\ ${ }^{2}$ Department of Mechanical Engineering, School of Systems Engineering, National Defense Academy, Japan. \\ ${ }^{3}$ Department of Earth and Environmental Engineering, Columbia University, USA.
}

\begin{abstract}
Strain rate effect of strength is a crucial factor for material characterization. Attempts have been made to evaluate strain rate effect by indentation tests. An indentation causes a non-uniform stress and strain field inside a specimen. This must induce a non-uniform strain rate field. However, little has been reported about strain rate distribution beneath the indenter. So far, various indenter control methods have been used. In previous studies, no direct comparisons were available as to how strain rate distribution was affected by different control methods. In this study, we report on the strain rate effect of indentation with two indenter control methods: constant loading rate (CLR) and constant indentation strain rate (CISR). The finite element method was designed to reproduce deformation caused by a conical indenter of a half apex angle of $70.3^{\circ}$. Pure aluminum (99.999 mass\% purity), which showed high strain rate dependence of strength, was chosen as a specimen. Material properties were obtained from low strain rate $\left(10^{-4}, 10^{-2} / \mathrm{s}\right)$ to high strain rate $\left(10^{2} / \mathrm{s}\right)$ tests, and results were incorporated into a FEM analysis using the Cowper-Symonds equation. Four constant loading rates (from 0.7 to $350 \mathrm{mN} / \mathrm{s}$ ) and constant indentation strain rates (from 0.006 to $6 / \mathrm{s}$ ) were used, and both results were compared. Differences between both indenter control methods were displacement-dependent. Loading curvature, which has been defined as a material constant in the indentation, was calculated from load divided by square of displacement. Although loading curvatures were decreased with increasing displacement for CLR, they were constant for CISR. Results also showed that values of strain rate decreased as displacement increased for CLR, whereas they were the same for CISR. Similarities of both indenter control methods were found as follows. The highest strain rate regions were observed at the edge of the indenter. In addition, higher strain rate region was distributed hemispherically from the edge of the indenter.

Keywords: finite element analysis, indentation, indentation strain rate, pure aluminum, strain rate, strain rate sensitivity.
\end{abstract}

\section{INTRODUCTION}

Indentation technique has been used for the mechanical characterization of materials. In a typical indentation test, a sharp indenter is shifted downward against a specimen, and the indentation load $(P)$ and displacement $(h)$ are continuously recorded. By using recorded data, the hardness $(H)$ can be obtained from the following equation [1]:

$$
H=\frac{P_{\max }}{A}
$$

where $P_{\max }$ is the maximum indentation load and $A$ is the projected contact area of the indenter.

Since a single indent is typically of a nano- or micrometer order, the indentation test can be applied on various materials such as metals, composites and polymers.

In the typical indentation test, sharp indenters such as conical, four-sided pyramid Vickers and three-sided pyramid Berkovich are being used frequently. Schematic images of these indenters are shown in Fig. 1. It has been observed that identical results can be obtained, if the effective area of the indenter (shaded area in Fig. 1) is the same [1]. In a simulation model, 

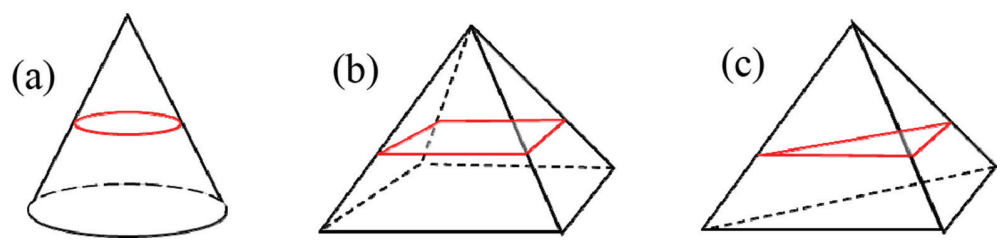

Figure 1: Schematic diagrams of sharp indenter (a) conical, (b) Vickers, (c) Berkovich.

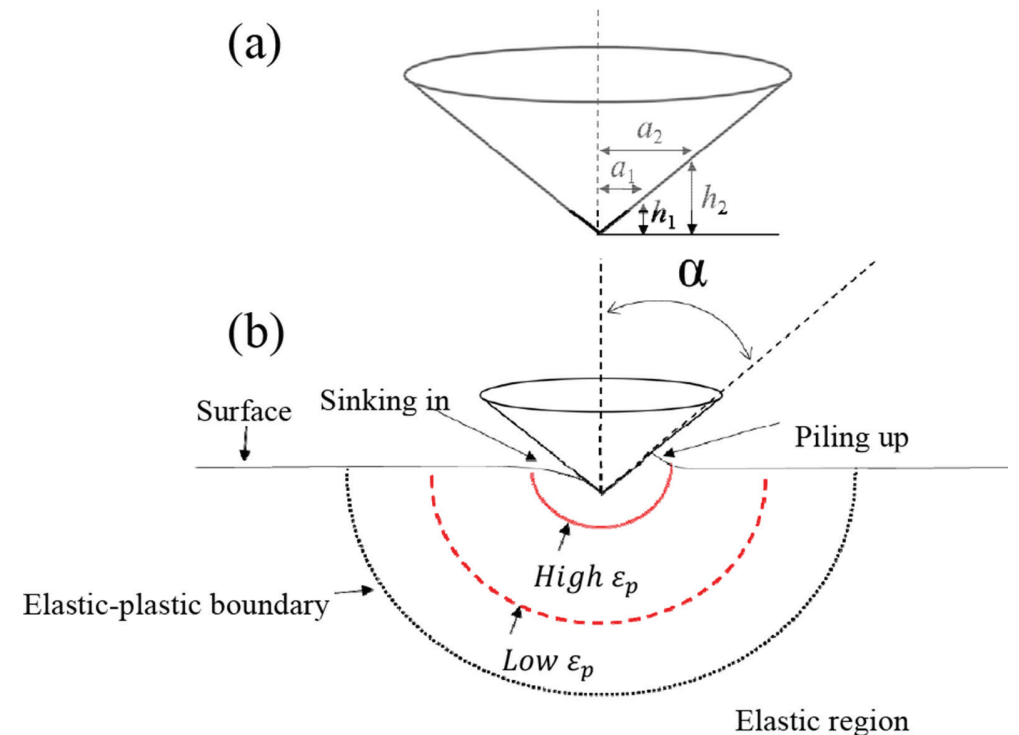

Figure 2: Schematic diagram of an indentation theory. (a) Concept of geometrical similarity [1];

(b) Plastic strain distribution [1].

the conical indenter has been used due to its asymmetrical shape, which produced the same results as that of a Berkovich indenter [2].

The sharp indenters induce the same elastic-plastic strain distribution regardless of the displacement (geometrical similarity) [3]. For example, in the case of a conical indenter, the contact radius to displacement ratio is the same regardless of the displacement $\left(a_{1} / h_{1}=a_{2} / h_{2}\right)$ [1], which is shown in Fig. 2a.

In addition, the elastic-plastic strain distribution beneath the indenter has been known to be hemispherical [4]. Schematic diagram of strain distribution beneath the indenter is shown in Fig. 2b. Experimental observations showed that high plastic strain $\left(\operatorname{High} \varepsilon_{\mathrm{p}}\right.$ ) was found near the tip of the indenter, and the value of the plastic strain gradually reduced at regions away from the tip (Low $\varepsilon_{\mathrm{p}}$ ), until its value meets the elastic-plastic boundary [5]. Chaudhri [6] investigated the plastic strain distribution beneath the indenter using annealed copper, and found that the plastic strain is as high as 0.36 at the tip of the indenter. Then, the plastic strain gradually reduced to almost zero at the region away from the indenter. Because indentation is influenced by elastic-plastic deformation, the shape of the deformed zone is dependent on the material properties [7]. Sinking in (surface pushed downward at the indenter edge) or piling up (surface piled up at the indenter edge) effect, shown in Fig. 2b, induces an error while measuring the true contact area. Thus, the accuracy of hardness has been debated [8,9]. 
Alternatively, indentation results have been evaluated using the loading curvature $(C)$, which is defined by the following equation $[2,10]$ :

$$
P=C h^{2}
$$

Static indentation experiment shows that the value of loading curvature is constant in a given material if the indenter angle is fixed [1].

Although the plastic strain distribution is not uniform, indentation tests can successfully characterize the mechanical properties of materials. Tabor [3] reported that the hardness obtained from the indentation test can be converted to the representative stress $\left(\sigma_{r}\right)$ through $H \approx 3 \sigma_{r}$. The representative stress was defined as the flow stress in a uniaxial test at plastic strain 0.08 for the Vickers indenter. This plastic strain was also defined as the representative strain of the indentation. This notion of the representative stress has been used with conical and Berkovich indenters with different values of the representative strain $[2,10]$. Using the representative stress, it is possible to estimate the tensile or compressive stress-strain curve through an indentation test $[2,10]$.

Various indentation simulations have been performed. Cheng and Li [11] have proposed parametric analysis of indentation and stated that indentation load was affected by Young's modulus $E$, Poisson's ratio $v$, work-hardening rate $n$ and indenter angle $\alpha$. The relationship between load and displacement can be written as follows [11]:

$$
P=E h^{2} \Pi(Y / E, \nu, n, \alpha)
$$

where is the dimensionless function.

Previous studies revealed that the effect of Poisson's ratio $v$ is small $[11,12]$. Cheng and $\mathrm{Li}$ [11] have conducted finite element simulations on conical indentations with wide ranges of material parameters. They studied the effect of material parameters on indentation. Investigated material parameters were $Y / E$ (ranged from 0.0002 to 0.1 ), work-hardening rate $n$ $(0,0.1$ and 0.5$)$ and indenter angle $\alpha\left(30^{\circ}, 45^{\circ}, 60^{\circ}, 70.3^{\circ}\right.$ and $\left.80^{\circ}\right)$. All of different combinations of material parameters and indenter angles were studied. Similarly, simulations of conical indentation were investigated using representative stress [10]. $E / \sigma_{r}$ was varied from 3 to 3300 covering most of the metals and $n$ was ranged from 0 to 0.5 . Investigated indenter angles were $63.14^{\circ}, 70.3^{\circ}$ and $75.79^{\circ}$. The study showed that $C / \sigma_{r}$ could lie on a single curve of $E / \sigma_{r}$ regardless of work-hardening rate. It was suggested that finite element analysis could be used for understanding the mechanism of indentation. However, these studies were limited to static indentation until now.

Strain rate effect of strength is a crucial factor for material characterization. Attempts have been made to evaluate strain rate effect by the indentation tests $[13,14]$. In a previous study [14], uniaxial compression and indentation experiments were conducted using pure aluminum 3N (99.9 mass\% purity) and 5N (99.999 mass\% purity). Experiments with wide ranges of the strain rate $\left(10^{-4} \sim 10^{3} / \mathrm{s}\right)$ revealed that pure aluminums have high strain rate dependence of strength.

Indentation tests were carried out using the same $3 \mathrm{~N}$ and $5 \mathrm{~N}$ aluminum by the constant loading rates with the Berkovich indenter. It is confirmed that indentation load increased as constant loading rate increased, and loading curvature was not constant for the pure aluminum. This suggested that classical indentation theory is not applicable in indentation with strain rate effect.

As mentioned earlier, an indentation causes non-uniform stress and strain field inside the specimen. This must induce a non-uniform strain rate field. However, little has been reported 
about strain rate distribution beneath the indenter (e.g. shape of strain rate distribution and strain rate value beneath the indenter). So far, various indenter control methods were being used. In a previous study, no direct comparisons were available on how strain rate distribution was affected by different control methods.

In this study, we report on the strain rate effect of pure aluminum, which showed high strain rate dependence of strength, using indentation with the finite element method. Two indenter control methods: the constant loading rate (CLR) and constant indentation strain rate (CISR) were investigated. Indentation results using two loading conditions were compared, and their differences were discussed. Finally, strain rate distributions were obtained, and the effects of two indenter control methods on indentation results were summarized.

\section{SIMULATION MODEL}

In this study, the finite element code ABAQUS/Standard (version 6.13,ABAQUS) was used to model the indentation test. Axisymmetric quadratic linear elements and large deformation options were adopted. A schematic image of model is shown in Fig. 3a. Roller boundary conditions were applied along the center and bottom line. Simulations were performed with a rigid indenter. Half apex of the conical indenter was $70.3^{\circ}$. This angle is frequently used since the same contact area is produced with that from common Vickers and Berkovich indenters. Friction coefficient between the indenter and material was set to be 0.15 , which was the friction value between metal and diamond [15]. However, the friction coefficient has little effect on indentation load if the indenter angle is greater than $60^{\circ}$ [16]. Meshes were designed to become finer closer to the indenter. The number of nodes was approximately 20,000 and the smallest mesh under the indenter was $0.08 \mu \mathrm{m}$ so that better convergences were achieved. Model sizes were determined in such a way that the size effects were negligible.

Strain rate effect is applied using the Cowper-Symonds equation [17]:

$$
\sigma(\varepsilon)=\sigma_{\mathrm{s}}(\varepsilon)\left[1+\left(\frac{\dot{\varepsilon}}{\gamma}\right)^{m}\right]
$$

where $\sigma_{\mathrm{s}}(\varepsilon)$ is static stress at referred strain. $\gamma$ and $m$ are strain rate parameters, which are defined as dynamic constants. Experiment results of $5 \mathrm{~N}$ aluminum (99.999 mass\% purity) at low strain rate $\left(10^{-4}, 10^{-2} / \mathrm{s}\right)$ and high strain rate $\left(10^{2} / \mathrm{s}\right)$ [18] were used. True stress-strain

(a)

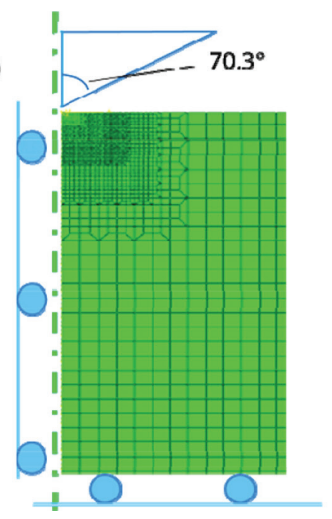

(b)

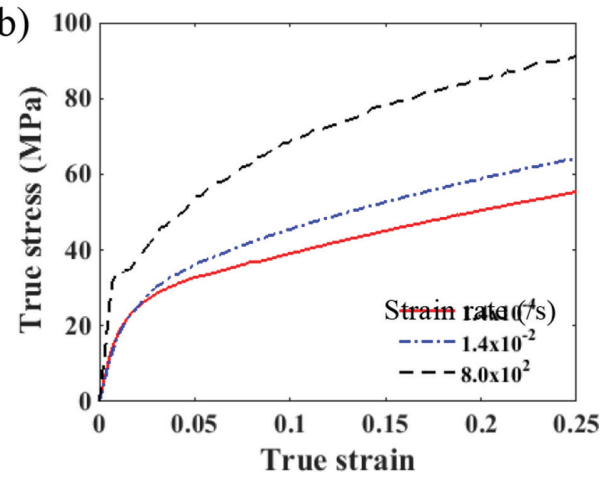

Figure 3: (a) Schematic image of model; (b) True stress-strain curves for $5 \mathrm{~N}$ aluminum at the low and high strain rate [18]. 
relationships were shown in Fig. 3b. Dynamic constants in eqn (4) were derived from Fig. $3 b$. Obtained $\gamma$ and $m$ were 5000/s and 0.16 , respectively.

\section{LOADING CONDITION}

\subsection{Theoretical equation for the loading conditions}

In general, indentation has been performed using 'Constant Loading Rate (CLR)' [1]. The maximum load is set and the value of CLR can be varied in experiments. In fact, strain rate effect was observed in indentation with different values of the CLR [14].

Indentation strain rate $\dot{\varepsilon}_{i}$ is defined as [19]:

$$
\dot{\varepsilon}_{i}=c\left(\frac{1}{h} \frac{d h}{d t}\right)
$$

where $c$ is a material constant and $t$ is test time. It has been reported that the hardness of material increased with decreasing indentation depth since the indentation strain rate $\dot{\varepsilon}_{i}$ increased [19].

Another loading condition is called the 'Constant Indentation Strain Rate (CISR)' and is given by the following equation [20]:

$$
\dot{\varepsilon}_{i c}=\frac{\dot{h}}{h}=\frac{1}{2} \frac{\dot{P}}{P}=\text { const } .
$$

where $\dot{\varepsilon}_{i c}$ is the CISR.

In order to achieve the CISR, the following function must be satisfied [21]

$$
h=h_{0} \exp \left(\dot{\varepsilon}_{i c} t\right)
$$

where $h_{0}$ is a displacement at $t=0$.

These two loading conditions were applied using the same model and material properties including Cowper-Symonds dynamic constants. This makes it possible to compare the effects of loading condition in the indentation test.

\subsection{Simulation conditions of constnat loading rate}

The maximum indentation load in this simulation was $1200 \mathrm{mN}$ and CLRs were set as 0.7, 7, 70 , and $350 \mathrm{mN} / \mathrm{s}$. These CLRs covered the conditions of previous indentation tests [14]. At the maximum load, the indenter force was maintained for $30 \mathrm{~s}$.

\subsection{Simulation conditions of constant indentation strain rate}

The initial displacement $h_{0}$ in eqn (7) was set to be $0.5 \mu \mathrm{m}$. The maximum displacement was chosen as $18.7 \mu \mathrm{m}$ in order to minimize the initial displacement effect. In preliminary simulations, different initial displacements with the fixed displacement $(18.7 \mu \mathrm{m})$ were also tested and indeed obtained almost identical results. By solving eqn (7) in terms of $\dot{\varepsilon}_{i c}$, the CISRs were set as $0.006,0.06,0.6$ and $6 / \mathrm{s}$. These CISRs were chosen to cover wide ranges of indentation strain rates used in previous studies [22,23]. Since the exponential function as defined by eqn (7), was not supported in the ABAQUS, the input function was approximated as 70 segments by using MATLAB. 


\section{SIMULATION RESULTS}

The relationship between load and displacement for CLR is shown in Fig. 4. In order to distinguish between the rate-dependent and rate-independent simulation, results without Cowper-Symonds equation was referred as 'independent' (e.g. $350 \mathrm{mN} / \mathrm{s}$ (Independent). In Fig. 4, the larger CLR indicated higher indentation load at a given displacement. Such an effect was not seen in the rate-independent results. For CISR, indentation loads were also increased similar to that of CLR (not shown here). Additionally, only rate-dependent results showed that displacement increased with increasing CLR during holding time in Fig. 4 (b). The relationships between loading curvatures and displacement are shown in Fig. 5. For CLR, loading curvatures were observed to remain constant in rate-independent results, whereas rate-dependent results showed that it decreased with the displacement as shown in Fig. 5a. The relationships between loading curvatures and displacement for CISR are shown in Fig. 5b, (for clarity, results during the initial displacement are excluded). Due to the approximation of exponential function, small fluctuations were observed, although such effect was small. Figure $5 \mathrm{~b}$ showed that loading curvatures remained constant regardless of strain rate effect in CISRs.

\section{GEOMETRICAL SIMILARITY}

\subsection{Geometrical similarity with strain rate effect}

The previous section suggested that the strain rate effect in an indentation test was influenced by different indenter controls. However, for CISR tests, the loading curvature of rate
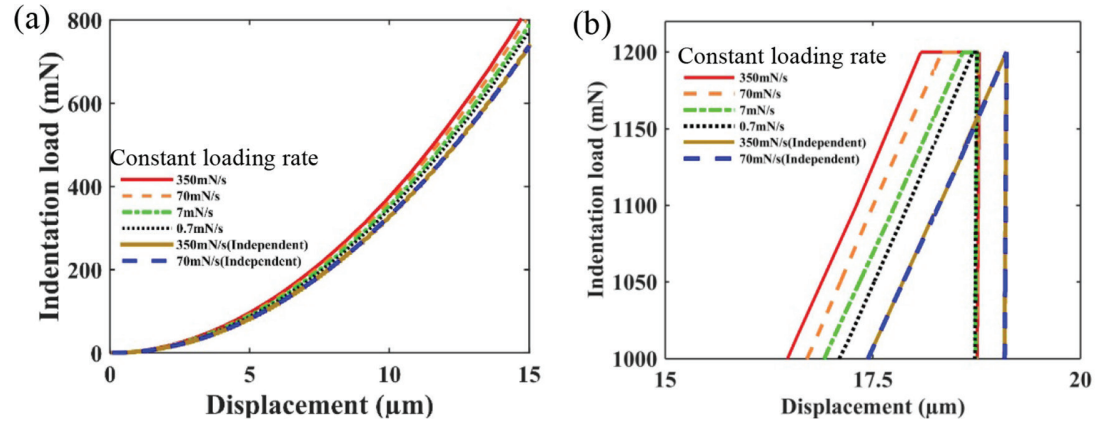

Figure 4: Relationship between indentation load and displacement for constant loading rate; (a) Load scale 0 to $800 \mathrm{mN}$ (b) Load scale 1000 to $1200 \mathrm{mN}$.
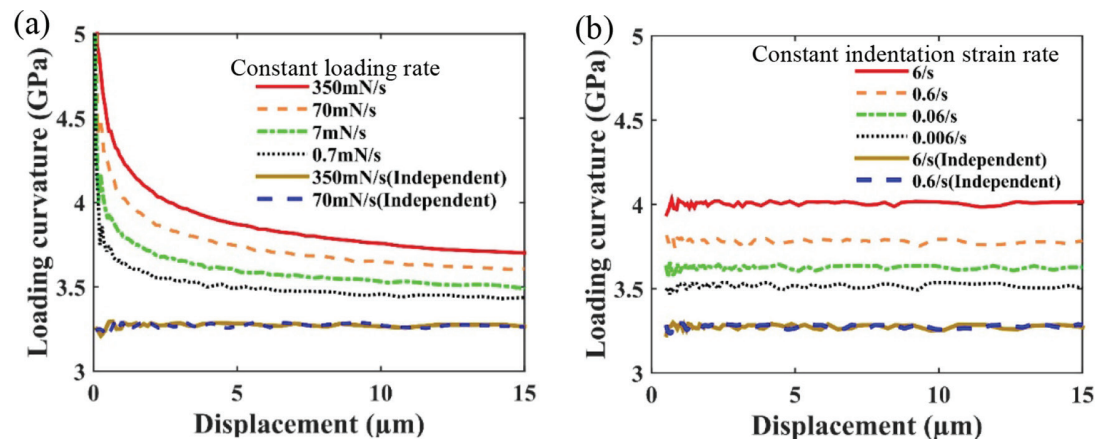

Figure 5: Relationship between loading curvatures and displacement. (a) Constant loading rates; (b) Constant indentation strain rates. 
(a)

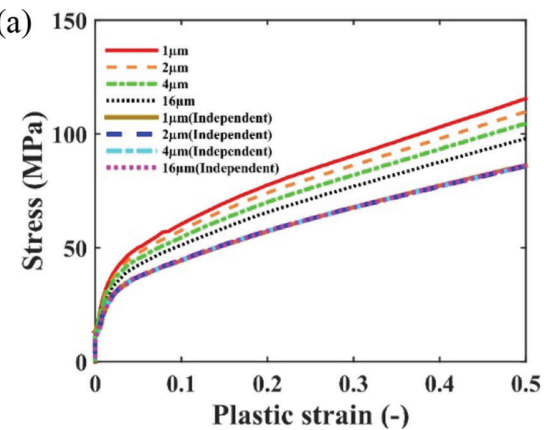

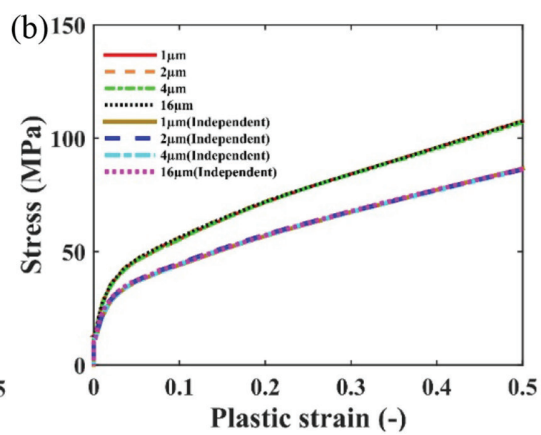

Figure 6: Relationship between stress and plastic strain under the indenter. (a) Constant loading rate $350 \mathrm{mN} / \mathrm{s}$; (b) Constant indentation strain rate $6 / \mathrm{s}$.

dependent materials showed the same behavior with that of rate independent materials. This means that it is possible that the classical indentation theory (e.g. geometrical similarity, which is based on $C=P / h^{2}=$ const.) can be applicable if the CISR method is used.

The geometrical similarity has been widely known for indenters such as the Berkovich and conical indenters. By using such indenters, the ratio of contact radius and depth is always constant during loading, and the hardness is independent of displacement due to geometrical similarity [1]. So far, geometrical similarity has not been investigated under the strain rate effect.

The relationship between stress and plastic strain beneath the indenter was derived. All of the results were obtained from von Mises stress and the equivalent plastic strain (hereinafter referred to as stress and plastic strain) from simulation results. Values of plastic strain were obtained vertically from the indenter, and certain displacements were arbitrarily chosen for comparison $(1 \sim 16 \mu \mathrm{m})$. Results are shown in Fig. 6a and b. Higher plastic strain indicates closeness to the indenter tip. Geometrical similarity is not applicable for the CLR with the rate-dependent material, because the stress and plastic strain relationship was dependent on the displacement. For example, stress reduction of approximately $15 \%$ was observed from 1 $\mu \mathrm{m}$ to $16 \mu \mathrm{m}$ as indicated in the Fig. 6a. On the other hand, geometrical similarity is valid for the following conditions:

1. Rate-independent results of CLR and CISR.

2. Rate-dependent results of CISR.

In order to investigate these points further, strain rate effect will be investigated in the following section.

\subsection{Geoemtrical similarity of strain rate}

In a previous study, little information was available for the geometrical similarity on strain rate. Strain rates were obtained by using two subsequent time increments. Strain rate is calculated from the following equation:

$$
\dot{\varepsilon}=\frac{d \varepsilon_{\mathrm{p}}}{d t}
$$

where $\varepsilon_{\mathrm{p}}$ is the equivalent plastic strain and $d t$ is the output time step of the simulation, which is about $30 \mathrm{~ms}$ in this study. 

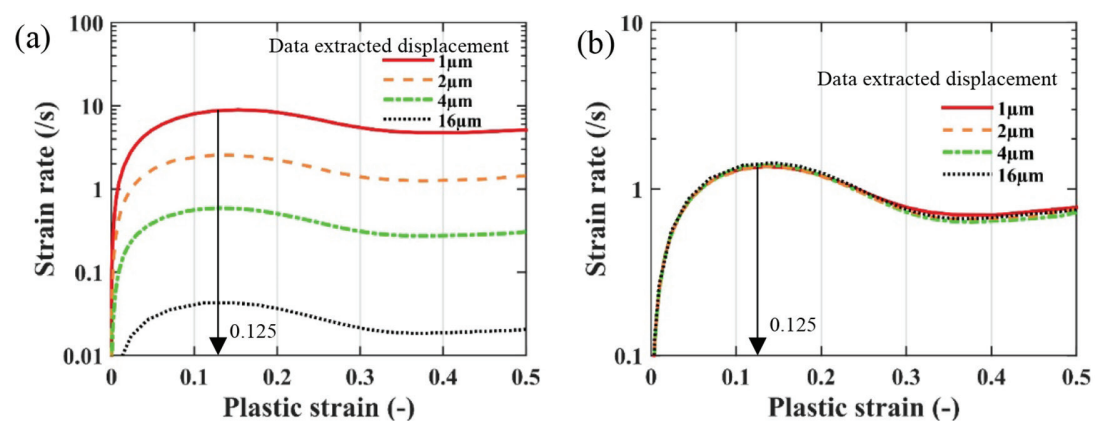

Figure 7: Relationship between strain rate and plastic strain under the indenter. (a) Constant loading rate $350 \mathrm{mN} / \mathrm{s}$; (b) Constant indentation strain rate 6/s.

Extractions of the data were made vertically from the indenter tip at arbitrarily chosen displacements (1 16 $\mu \mathrm{m})$. Simulation results of CLR and CISR are shown in Fig. 7a and (b). The strain rates of CLR in Fig. 7a clearly showed that strain rate was dependent on the displacement, whereas those of CISR in Fig. $7 \mathrm{~b}$ indicated that the strain rate was independent of displacement. This supports the assumption that the geometrical similarity on strain rate is also valid for the CISR. This is the reason why the geometrical similarity with strain rate effect is only applicable for CISR as shown in Fig. 6 b.

In addition, the highest strain rate was observed at plastic strain 0.125 for both indenter control methods. It is interesting to note that this value is close to the representative strain 0.08 as Tabor has suggested [3]. However, further investigation is necessary to clarify the physical meaning of this finding.

Figure 7 shows that high strain rate gradient is obtained at low plastic strain 0 to 0.1 . In contrast, low strain rate gradient was observed at high plastic strain (e.g. 0.3 to 0.5). As shown in Fig. $2 \mathrm{~b}$, the area of plastic strain 0 to 0.1 (Low $\varepsilon_{p}$ ) should be large in comparison with that of high plastic strain 0.3 to 0.5 (High $\varepsilon_{p}$ ). This means that high strain rate gradient affects a large area of the specimen during indentation. A similar conclusion was obtained for all indenter velocity.

\section{ANALYSIS OF STRAIN RATE DISTRIBUTION IN INDENTATION}

\subsection{Strain rate distribution}

In order to obtain a general idea on the strain rate distribution, strain rate diagrams are depicted in Fig. 8. It can be observed that strain rate is distributed hemispherically.

As shown in Fig. 2b, the highest plastic strain is found at the tip of the indenter. In contrast, the highest strain rate was located at the edge of the indenter as shown in Fig. 8. This is because new surface is always deformed as indenter penetrates. Additionally, higher strain rate region was observed from indenter radius, which was approximately 2 to 5 times larger than the displacement.

Figure $8 \mathrm{a}$ and $\mathrm{b}$ showed that the CLR produced smaller strain rate at larger displacement. However, the strain rate values were the same for the CSIR.

\subsection{Strain rate of indentation}

Actual strain rate values that affect material have been debated in previous studies [24, 25]. It was revealed that strain rate is distributed non-uniformly as explained in the previous sec- 

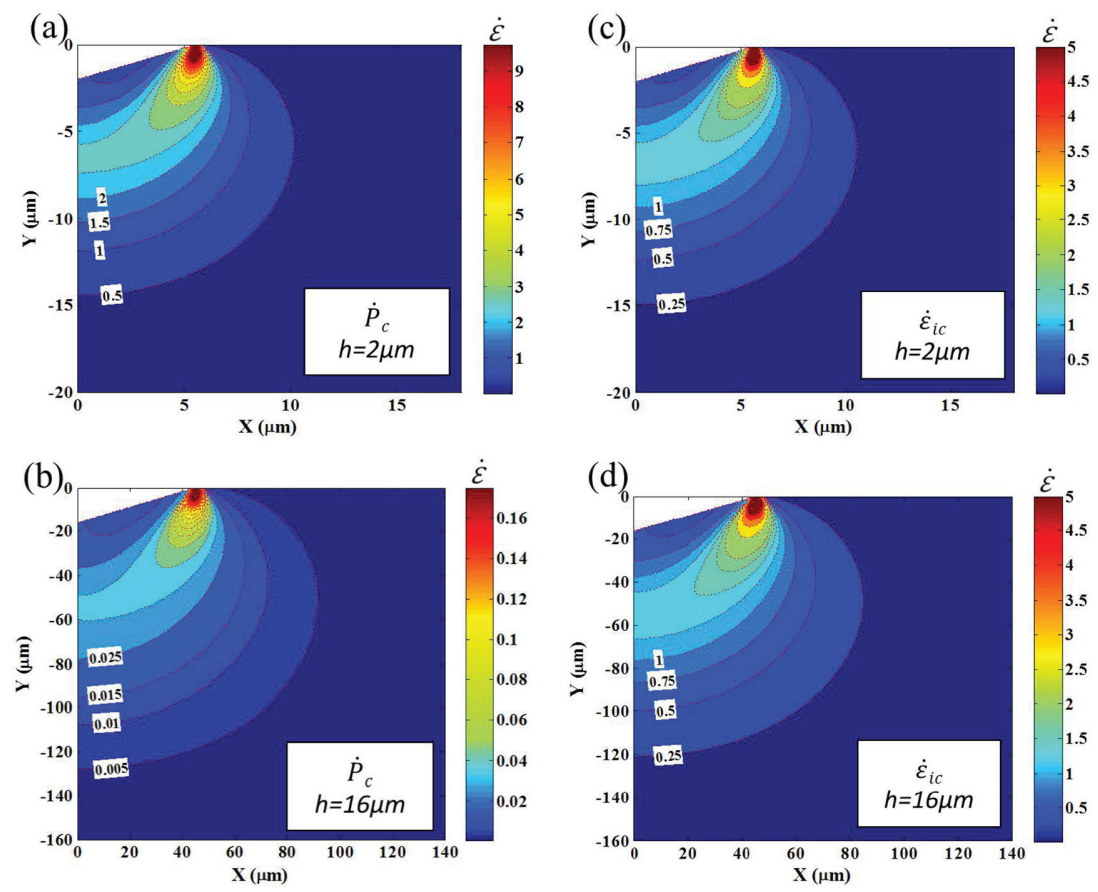

Figure 8: Strain rate diagrams at certain displacements $(h=2 \mu m$ and $16 \mu m)$ given by different testing methods. (a), (b) The constant loading rate $(350 \mathrm{mN} / \mathrm{s})$; (c), (d) The constant indentation strain rate $(6 / \mathrm{s})$.

tion. Unlike in a uniaxial test, obtaining the single value of strain rate is difficult in indentation. It is therefore of technical interest to seek a reference strain rate that can correlate with the strain rate of a uniaxial test [25]. The relationship between the strain rates of uniaxial tests and constant indention strain rates can be approximated as:

$$
\dot{\varepsilon}=b \dot{\varepsilon}_{i c}
$$

where $b$ is a material constant [25].

It has been assumed theoretically that $b$ in eqn (9) ranges from 0.071 to 0.286 depending on material properties [25]. Our results suggested that strain rate of CLR is found to be decreasing with increasing displacement. Obtaining a reference strain rate for the CLR is difficult since it reduces with displacement. Here, we focused on the CISR, since the strain rate distribution was the same regardless of the displacement. The highest strain rate from Fig. $7 \mathrm{~b}$ was derived, and $b$ was 0.23 , which was within the ranges mentioned earlier. As the present study has suggested, strain rate distribution is not uniform, and is different from plastic strain distribution. More detailed work is necessary to relate indentation strain rate with strain rate of uniaxial tests.

\section{CONCLUSIONS}

Strain rate effects of indentation is an important material characterization, although the effect of loading condition has been unknown. In this study, strain rate effects of indentation with different indenter controls were investigated using the finite element method. Results were summarized as follows. 


\section{For CLR,}

1. Loading curvatures decreased with increasing displacement.

2. Geometrical similarity was not applicable with strain rate effect.

3. Value of strain rate decreased with displacement.

\section{For CISR,}

1. Loading curvatures were constant regardless of the displacement.

2. Geometrical similarity was applicable with and without strain rate effect.

3. Value of strain rate was the same regardless of the displacement.

Similarities of both control methods were listed as follows.

1. The highest strain rate regions were observed at the edge of the indenter.

2. Higher strain rate region was distributed hemispherically from the edge of the indenter.

It was clarified that strain rate in indentation was strongly affected by the loading conditions. Constant indentation strain rate was suitable to relate the strain rate value with that of uniaxial test since those were the same regardless of the displacement. However, further study is necessary to correlate the indentation strain rate with uniaxial strain rate.

\section{ACKNOWLEDGMENTS}

This work was supported by JSPS KAKENHI Grant Number 25709004. The authors also wish to thank the Light Metal Educational Foundation, Inc., Osaka in Japan for its financial support.

\section{REFERENCES}

[1] Fischer-Cripps, A.C., Nanoindentation Third Edition, Springer New York, 2011. https://doi.org/10.1016/B978-0-12-387667-6.00013-0

[2] Dao, M., Chollacoop, N., Van Vliet, K.J., Venkatesh, T.A. \& Suresh, A., Computational modeling of the forward and reverse problems in instrumented sharp indentation. Acta Materialia, 49(19), pp. 3899-3918, 2001. https://doi.org/10.1016/S1359-6454(01)00295-6

[3] Tabor, D., The physical meaning of indentation and scratch hardness. British Journal of Applied Physics, 7, pp. 159-166, 1956. https://doi.org/10.1088/0508-3443/7/5/301

[4] Johnson, K.L., The correlation of indentation experiments. Journal of the Mechanics Physics of Solids, 18(1), pp. 115-126, 1970. https://doi.org/10.1016/0022-5096(70)90029-3

[5] Mulhearn, T.O., The deformation of metals by vickers-type pyramidal indenters. Journal of Mechanics and Physics of Solids, 7(2), pp. 85-88, 1959. https://doi.org/10.1016/0022-5096(59)90013-4

[6] Chaudhri, M.M., Subsurface strain distribution around vickers hardness indentations in annealed polycrystalline copper. Acta Materialia, 46(9), pp. 3047-3056, 1998. https://doi.org/10.1016/S1359-6454(98)00010-X 
[7] Branch, N.A., Arakere, N.K., Subhash, G. \& Klecka, M.A., Determination of constitutive response of plastically graded materials. International Journal of Plasticity, 27(5), pp. 728-738, 2011. https://doi.org/10.1016/j.ijplas.2010.09.001

[8] Kese, K.O., Li, Z.C. \& Bergman, B., Influence of residual stress on elastic modulus and hardness of soda-lime glass measured by nanoindentation. Journal of Materials Research, 19(10), pp. 3109-3119, 2011. https://doi.org/10.1557/JMR.2004.0404

[9] Cabibbo, M., Ciccarelli, D. \& Spigarelli, S., Nanoindentation hardness measurement in piling up SiO2 coating. Physics Procedia, 40, pp. 100-112, 2013. https://doi.org/10.1016/j.phpro.2012.12.014

[10] Ogasawara, N., Chiba, N. \& Chen, X., Representative strain of indentation analysis. Journal of Materials Research, 20(08), pp. 2225-2234, 2005. https://doi.org/10.1557/JMR.2005.0280

[11] Cheng, Y. \& Li, Z., Hardness obtained from conical indentations with various cone angles. Journal of Materials Research, 15(12), pp. 2830-2835, 2000. https://doi.org/10.1557/JMR.2000.0404

[12] Mesarovic, S.D. \& Fleck, N.A., Spherical indentation of elastic-plastic solids. Proceeding of the Royal Society London A, 455, pp. 2707-2728, 1999. https://doi.org/10.1098/rspa.1999.0423

[13] Ma, X., Yoshida, F. \& Shinbata, K., On the loading curve in microindentation of viscoplastic solder alloy. Materials Science and Engineering: A, 344, pp. 296-299, 2003. https://doi.org/10.1016/S0921-5093(02)00442-2

[14] Yamada, H., Ogasawara, N., Shimizu, Y., Horikawa, K., Kobayashi, K. \& Chen, X., Effect of high strain rate on indentation in pure aluminum. Journal of Engineering Materials and Technology, 135(2), p. 021010, 2013. https://doi.org/10.1115/1.4023778

[15] Bowden, F.P. \& Tabor, D., The Friction and Lubrication of Solids, Clarendon Press, Walton Street, Oxford OX2 6DP, UK, 1986.

[16] Bucaille, J.L., Stauss, S., Felder, E. \& Michler, J., Determination of plastic properties of metals by instrumented indentation using different sharp indenters. Acta Materialia, 51(6), pp. 1663-1678, 2003. https://doi.org/10.1016/S1359-6454(02)00568-2

[17] Cowper, G.R. \& Symonds, P.S., Strain hardening and strain-rate effects in the impact loading of cantiliver beams. Brown Univ., Div. Appl. Mech., Report,. 28, 1957.

[18] Yamada, H., Midori, H., Kami, T., Ogasawra, N. \& Chen, X., Effect of dynamic strain rate on micro-indentation properties of pure aluminum. EPJ Web Conferences, 94, 04034, 2015. https://doi.org/10.1051/epjconf/20159404034

[19] Doerner, M.F. \& Nix, W.D., A method for interpreting the data from depth-sensing indentation instruments. Journal of Materials Research, 1(4), pp. 601-609, 1986. https://doi.org/10.1557/JMR.1986.0601

[20] Mayo, M.J. \& Nix, W.D., A micro-indentation study of superplasticity in $\mathrm{Pb}, \mathrm{Sn}$, and Sn-38 wt\% Pb. Acta Metall, 36(8), pp. 2183-2192, 1988. https://doi.org/10.1016/0001-6160(88)90319-7 
[21] Andrews, E.W., Giannakopoulos, A.E., Plisson, E. \& Suresh, S., Analysis of the impact of a sharp indenter. International Journal of Solids and Structures, 39, pp. 281-295, 2002. https://doi.org/10.1016/S0020-7683(01)00215-3

[22] Guo, Y.Z., Behm, N.A., Ligda, J.P., Li, Y.L., Pan, Z., Horita, Z. \& Wei, Q., Critical issues related to instrumented indentation on non-uniform materials: application to niobium subjected to high pressure torsion. Materials Science and Engineering: A, 586, pp. 149-159, 2013.

https://doi.org/10.1016/j.msea.2013.08.015

[23] Lucas, B.N. \& Oliver, W.C., Indentation power-law creep of high-purity indium. Metallurgical and Materials Transaction A, 30A, pp. 601-610, 1999.

https://doi.org/10.1007/s11661-999-0051-7

[24] Alkorta, J., Manuel, M.E.J. \& Sevillano, J.G., On the elastic effects in power-law indentation creep with sharp conical indenters. Journla of Materials, Research, 23(1), pp. 182-188, 2008.

https://doi.org/10.1557/JMR.2008.0011

[25] Poisl, W.H., Oliver, W.C. \& Fabes, B.C., The relationship between indentation and uniaxial creep in amorphous selenium. Journal of Materials Research, 10(08), pp. 2024 2032, 1994.

https://doi.org/10.1557/JMR.1995.2024 